\title{
Gender Roles, Child Moves and Parental Well-being A Panel Study on Short and Long Term Effects for Germany
}

\author{
Matthias Collischon ${ }^{1,2}$, Andreas Eberl ${ }^{1}$, Tobias Wolbring ${ }^{1}$ \\ Order of author names reflects equal authorship \\ ${ }^{1}$ FAU Erlangen-Nürnberg, Chair of Empirical Economic Sociology, Findelgasse 7/9, 90402 Nürnberg \\ ${ }^{2}$ Institut für Arbeitsmarkt- und Berufsforschung (IAB), Research Department E3, Regensburger Straße 100, 90478 Nürnberg
}

March 10, 2021

\begin{abstract}
This article investigates the effect of adult children leaving the parental home on parental well-being. Adult children moving out is an important event in parents' lives. However, it is theoretically unclear whether parental well-being decreases or increases from children moving out. Children moving out can relief parents' burdens (e.g. housework) and lead to a change in parental roles, with adverse consequences for parental well-being. This study uses long-running panel data (1991-2016) from the German Socio-Economic Panel (SOEP) to investigate the relationship between child move and parental well-being using fixed effects dummy impact functions. The findings suggest that differentiating between first and empty nest moves is important when investigating the effects of children moving out of the parental home on parental well-being, as only the first move shows a long lasting negative effect on parental well-being. Furthermore, the effects are strongest for respondents who follow traditional gender roles.
\end{abstract}

Keywords: empty nest, SOEP, life satisfaction, role identity, role strain, panel data, fixed effects 


\section{Introduction}

Moving out from home is a major stepping stone to independence for most young adults. However, the departure from home not only shapes children's but also parents' life in important ways. After decades of raising a child and enjoying family life, parents face an empty nest and have to adjust to the new situation with potentially important implications for their subjective well-being in this post parental period - a period that becomes longer in ageing societies. On the one hand, the empty nest might lead to "a period of depression, identity crises, adjustment, confusion, role loss, and a lowered sense of well-being" (Borland, 1982). On the other hand, parents have the home for themselves after the launching of the last child and can use their free time and space for leisure. It is thus an open empirical question whether and in what way the empty nest syndrome affects parental well-being.

From a sociological perspective, adult children leaving home can affect parental well-being through mainly two channels: role identity and role strain. According to the role identity channel, being a mother or father is a social role. The way how this role can be fulfilled changes when children leave the parental home and might, at least in the beginning, leave a gap requiring readjustment. This change of an essential role should be associated with a decline in well-being (Thoits, 1983) and should be especially strong for mothers (for an overview see Bouchard, 2014). However, according to the role strain channel, children in the parental home can also provoke conflicts between demands from different life domains, in particular work, leisure, and family (Erickson, et al., 2010, Gunderson and Barrett, 2017, for an overview see Nomaguchi and Milkie, 2020). An empty nest can attenuate these strains and might lead to an increase in life satisfaction. Thus, each of these theoretical considerations provides a clear prediction on the effect on well-being. However, taken together, the interplay of these two channels can lead to a positive, a negative or a null effect. 
Empirical results on the empty nest effect are inconsistent (for an overview see Bouchard, 2014). While a small number of studies finds negative effects on parental well-being, the majority reports null or even positive effects (e.g. Becker, et al., 2019, White and Edwards, 1990). Furthermore, the literature also does not provide a clear picture whether the empty nest effect is stronger for mothers or fathers. While a large part of the literature argues, in line with intuition and role theory, that mothers suffer more from an empty nest (e.g. Glenn, 1975, Sheriff and Weatherall, 2009), there are studies reporting even stronger effects for fathers (e.g. Back, 1971, see Barber, 1989).

However, in contrast to more recent research on parenthood and well-being (for an overview see Nomaguchi and Milkie, 2020) such as studies on intergenerational co-residence (e.g. Caputo, 2019), home leaving and returning of children (e.g. Tosi and Grundy, 2018), and helicopter parenting (e.g. Fingerman, et al., 2012, Reed, et al., 2016), studies on the empty nest effect within the last decades are rather scarce. Against the changing context of emerging adulthood and parenting cultures in the U.S. and many European countries since the 1980s (see Nomaguchi and Milkie, 2020), this research gap appears particularly noteworthy. Due to the changing economy that requires higher skills, which requires more schooling, to have a decent job, the transition of young adults to economic independence of parents after leaving home is not always smooth and often involves parents' emotional and financial support (Danziger and Ratner, 2010).

Another potential reason why the evidence on the empty nest syndrome is so mixed and deserves a closer look is that most studies focus on the launching of the last child from home or do not distinguish between empty nests and the first child moving out. However, the processes at play do not necessarily materialize during the empty nest period, but earlier, with the first child leaving the parental home. Potentially, the first child leaving home - this stage is often termed launching phase in the literature (Bouchard, 2014) - already gives rise to both, 
role identity changes and role strain, a view that has been largely ignored in the previous literature. On the one hand, the first child moving out could give rise to a feeling of role change in parents, as they already feel their parental roles fading and anticipate the empty nest. On the other hand, it could also lead to a relief of role strain, because conflicts between work, family, and leisure decrease. Finally, another important reason that might cause these inconsistent results are the methodological limitations of most previous studies. Most of the literature relies on cross-sectional data and, hence, cannot answer the question how parental well-being changes after the children have moved out. Due to the cross-sectional comparison of empty nest households with households with children at home, previous results might suffer from biases due to selection and unobserved heterogeneity.

In this paper, we take the case of Germany to investigate the effects of the launching phase and the empty nest period on the subjective well-being of both fathers and mothers. Germany is an interesting case for several reasons. In Germany, the male breadwinner model is still dominant, while female labor market participation is at a relatively low level (Grunow, et al., 2018). At the same time, despite the reunification of East and West Germany, important differences in culture, gender norms, and institutional support of parents persist (Pfau-Effinger and Geissler, 2002) allowing a quasi-experimental test on the role of norms and culture. This is also possible for Germany because rich longitudinal data are available with the German Socio-Economic Panel (SOEP) which contains detailed information on overall and domain-specific satisfaction.

Against this background, this paper aims to contribute to the literature in three ways. First, we distinguish in our analysis between the start of the launching phase (i.e. the first child moving out) and empty nest moves (i.e. the last child moving out). Using fixed effects dummy impact functions we not only control for selection effects but also assess the effects over time and capture adaption processes. Second, we investigate differences for mothers and fathers, as parental roles differ by gender, and we test potential mechanisms to get a better understanding 
of the underlying processes. Third, we use long-running panel data from the SOEP to investigate the dynamic impact of children leaving home on parental well-being, measured as life satisfaction. As a large share of the literature relies on cross-sectional analysis, we also contrast our findings from fixed effects regressions to classical OLS-models to assess the importance of potential biases through unobserved heterogeneity that influences cross-sectional analyses.

\section{Role Identity, Role Strain and Well-Being}

This section provides an overview on the channels of role identity and role strain to derive hypothesis on the impact of children leaving home on parental well-being.

\section{Role identity}

Role identity theories are based on the school of symbolic interactionism, which assumes that each person has a variety of identities. These identities are important to develop personality and social behavior (Thoits, 1983). Individuals are placed in social positions, which include reciprocal role expectations. Role expectations force individuals to constantly imagine what is expected of them in their current role by taking on the perspective of the generalized others (Mead, 1934). Thus, roles can also be described as expectations attached to positions of social relationships, whereas identities are the internalized expectations of these roles (Stryker, 2002). The number of identities which each individual holds depends on the sets of social relations in which he/she plays a certain role (Stryker, 2002).

Role requirements are important for individual well-being, because they provide guidance for one's life: "if one knows who one is (in a social sense), then one knows how to behave” (Thoits, 1983). However, social identities and the roles accompanied are not equally important for individuals (Stryker and Serpe, 1982) and commitment to some roles is greater than to others (Thoits, 1991). Not being able to fulfill a central social role (e.g. parental role after children 
have left home) on a satisfactory level should decrease psychological well-being due to the loss of guidance, meaning and direction (Thoits, 1983). This line of thought goes back to Durkheim (1951) who already pointed out the importance of parenthood because the parental role structures people's life and integrates them into social structure.

As parenthood is an important part of parents' identity, it should be directly linked to subjective well-being (see Hansen, 2012). Scott and Alwin (1989) describe that the parental role encompasses different tasks such as looking after the children, spending time on household duties and connecting the household to parts outside of the household (e.g. through employment). Regarding adult children leaving the parental home, the theory predicts a negative impact on parental well-being (Borland, 1982, Bouchard, 2014, White and Edwards, 1990). The parental role becomes less important and cannot be lived out to the same extent as before one's children leave home (Barber, 1989).

However, the role loss induced by children leaving home could be (partially) buffered by an additional working role. While parents who hold a working role simultaneously can fulfill the additional role even after adult children have left home (Mitchell and Lovegreen, 2009), parents who exclusively focus on the parental role cannot fulfill their role to the same extent as before, leading to lower levels of well-being. Thus, the negative effect of child leave on parental wellbeing could be smaller, if parents have an additional working role. Based on the role identity channel, we derive the following hypothesis: Child leaving reduces parental well-being, especially for parents without a compensating working role (Hypothesis 1).

\section{Role strain}

Role engagement goes along with burdens and benefits (Marks, 1977, Pearlin, 1989, Sieber, 1974). Overall, the burdens of the parental role can easily exceed the benefits and result in role strain. In comparison to role identity, the role strain channel suggests that the departure of children improves parental well-being because children at home are potential stressors due to 
family conflicts, time constraints, and other daily demands (Bouchard, 2014). This is line with research showing that parental stress levels increase again when children move back to their parents' home (e.g. Tosi, 2020, Tosi and Grundy, 2018).

Children moving out could affect well-being mainly for three reasons. First, having adolescent children in the household goes along with family-work conflicts (e.g. Grzywacz, et al., 2002), which lower parental well-being. In general, the degree of role strain depends on the stress level and the potential conflicts that come along with a specific role (Barnett and Baruch, 1985, Pearlin, 1989, White and Edwards, 1990). Various studies show that parenthood is stressful (e.g. Erickson, et al., 2010, Gunderson and Barrett, 2017, Reczek and Zhang, 2016, Twenge, et al., 2003, Umberson, et al., 2010). Although some studies report that work-family conflicts become less important with the age of the children (Seiffe-Krenke, 2006), others show that conflicts increase and potential conflicts between parents and children at home remain (Knoester, 2003). For example, frequent contact between parents and adult children with a poor relationship living in the same household negatively affects parental well-being (Knoester, 2003). Nomaguchi (2012) shows that parents whose oldest child is under age five report higher levels of satisfaction with the relationship with their children than those with adult children. Further, parents with children under age five show lower levels of depression than those with pre-school or adult children. The author concludes that parents with pre-school or adult children may face interpersonal conflicts with their children, which result in higher levels of depression. When children leave home, these potential conflicts within the family decrease, which should result in increased satisfaction with family life.

Second, daily demands such as housework and childcare are an integral part of the parental role (Umberson, et al., 2005). Thus, when children leave home, it reliefs responsibilities of day-today caring and increases freedom (Barber, 1989). As research reveals, spouses have difficulties to find private time to spend together if children live in the same household (Anderson, et al., 
1983). Thus, a part of the positive effect of child leave on life satisfaction could be mediated by a relief in daily demands such as housework and an increase in leisure time.

Third, financial burdens may explain parental role strain. When children find a job and leave the parental home, costs caused by the children like daily food, heating, and vacations are reduced. For example, Pollmann-Schult (2014) shows that life satisfaction-enhancing effects through children are suppressed by economic burdens that are associated with parenthood. If these economic burdens are reduced by child leave, a positive mediation effect of satisfaction with household income is expected. However, recent economic developments, especially after the Great Recession, indicate that economic independency from ones' parents becomes harder over time (e.g. Danziger and Ratner, 2010). Thus, if the child move is accompanied by an increase in financial burdens for parents because children need financial support after leaving parental home, this could also negatively impact parental life satisfaction.

Against this backdrop, a child move should increase parental well-being because it reliefs role strains (e.g. Glenn, 1975, Glenn and McLanahan, 1982, White and Edwards, 1990). Consequently, parents have more time and energy for other parts of life (Gorchoff, et al., 2008). Therefore, the role strain channel suggests that the child leave increases parental well-being due a relief in family conflicts, housework and financial burdens (Hypothesis 2). 


\section{Heterogeneities across subgroups}

Based on theoretical considerations as well as previous empirical results, we examine the impact of three important factors: i) abrupt change or gradual process, ii) differences between mothers and fathers and iii) east/west differences.

\section{Abrupt change or gradual transition}

Some researchers differentiate between the launching phase and the empty nest transition (Bouchard, 2014). The launching phase refers to the stage when the first child starts to move out of the parental home. In contrast, the empty nest phase describes the stage after all children have left the home. As will become clear in the following, this distinction is important even though large part of the literature either mix both types of moves or exclusively focus on the empty nest transition. A priori, it is unclear whether the effects of role identity changes materialize during the launching or the empty nest phase. On the one hand, one could argue that, as long as there are still children in the household, the parental role is meaningful and that the role only changes when there are no children left in the parental home. Thus, it seems reasonable that the empty nest move has a stronger negative effect on parental life satisfaction than the first move.

On the other hand, the parental role could already shift with the beginning of the launching phase, since it signals to the parents the possibility of an empty nest in the near future. In line with this, Barber (1989) characterizes the empty nest transition as a gradual process rather than an abrupt change. Against this backdrop, it seems reasonable that the parental role change already starts or at least is anticipated with the beginning of the launching phase and already affects subjective well-being before the nest is actually empty. Besides such anticipation effects, adaptation could also be at work. While the move of the first child might involve a lot of uncertainty for the parents (e.g., regarding how close the contact will be and whether the child will get along on its own), expectations are much clearer when the second or third child leaves 
the home. As a consequence, parents can already rely on certain routines of how to cope with situation. This would imply that the first child move has the strongest negative influence on parental well-being and empty nest moves are less important for parental well-being due to anticipation and adaption processes.

Such anticipation and adaptation effects are well-documented in subjective well-being research for other life events such as birth of first child (Switek and Easterlin, 2018), marriage (Lucas and Clark, 2006), housing moves (Wolbring, 2017), retirement (Merz, 2018), and unemployment (von Scheve, et al., 2017). Thereby, the degree of uncertainty about the future caused by an event seems to moderate the extent of adaptation to new circumstances (see Graham, 2011). While people seem to adjust to changes involving certainty, empirical evidence suggests that it is much harder for them to adapt to an uncertain future. Given this theoretical considerations, the first move should have a stronger negative effect on parental life satisfaction than the empty nest moves.

\section{Differences between mothers and fathers}

Gender differences regarding children leaving home are not as clear-cut as they might seem at first glance. Harkins (1978) argues that the child move should especially harm the well-being of mothers, because the role of the mother has traditionally been central for most women. Other studies argue that mothers have dedicated many years and put in a great amount of time into child rearing, which should result in greater distress induced by the role identity change (Mitchell and Lovegreen, 2009, Raup and Myers, 1989). Gender beliefs and role expectations of others towards mothers often mirror these assumptions in social interactions (see Ridgeway and Correll, 2004).

In line with these traditional gender norms and beliefs, the implicit assumption of the literature on empty nest effects is that many fathers hold additional roles beside the parental one and have a weaker bond with their children. If one is willing to assume that traditional gender norms are 
still widespread in German society, it seems reasonable that a child leave has a larger negative impact on mothers' than on fathers' life satisfaction.

Similarly, the role strain channel suggests that mothers are particularly affected when children leave home, as mothers usually have greatest responsibility for their children (Twenge, et al., 2003). For example, Barnett and Baruch (1985) as well as Musick, et al. (2016) argue that the parental role is strongly related to strain for mothers. This is in line with empirical findings, which show that women particularly benefit from the relieved role strains and therefore increased well-being (for an overview see Bouchard, 2014, e.g. Glenn, 1975). Thus, mothers should experience a higher increase in well-being when children leave home than fathers due to a decrease in child related burdens.

However, some scholars argue that fathers should experience a similar decline in well-being due to child leave as mothers. Due to the traditional role of fathers as breadwinner who spends, on average, less time at home than mothers, fathers may regret lost opportunities for building a relationship with their children. For example, some fathers report that they had failed to take advantage of the time when children were at home (Barber, 1989) and regret that they were absent (Sheriff and Weatherall, 2009). Milkie, et al. (2019) show that almost half of employed parents report that time with their children is too sparse. Thus, the negative effect of child leave on well-being might be not a purely maternal phenomenon, but could also substantially affect fathers (Barber, 1989, Mitchell and Lovegreen, 2009). Therefore, in contrast to our theoretical considerations before, child moves could have a similar negative impact on fathers' as on mothers' life satisfaction.

Nevertheless, fathers could also experience role strain. As fathers typically work full-time, balancing work and family life could be just as stressful for them as for mothers. When adult children move out, balancing work and family life could become easier for fathers due to the 
relief of work-family conflicts. Thus, this implies that fathers experience an increase in wellbeing similar to mothers when children move out.

\section{East/west}

Gender norms and gender ideologies differ widely between and within countries (Grunow, et al., 2018). Within Germany, historically deep rooted differences in gender roles persist between East and West Germany (Pfau-Effinger and Geissler, 2002). While the German Democratic Republic (GDR) in East Germany fostered a dual breadwinner/state-career model in which mothers were full-time employed, the Federal Republic of Germany (FRG) in West Germany favored a male breadwinner model, which relegated mothers to unpaid housework.

These differences led to better institutional childcare facilities in East Germany than in West Germany, which relieved parents of their care duties and fostered mothers' labor market participation (Rosenfeld, et al., 2004, Schober and Spiess, 2015). Differences in gender roles regarding labor market and family between East and West Germany are still present. East Germans are more likely to hold egalitarian gender role attitudes than West Germans. Although one might assume that the differences in gender roles converge over time, the opposite seems to be the case. The differences even increase in some aspects (Bauernschuster and Rainer, 2012).

Those differences do not only affect parenthood in early childhood but also have a profound effect on gender and parental roles in later age. In contrast to West Germany, where oftentimes mothers have no working role in addition to their parental role, in East Germany mother more frequently work part- or full-time (Zoch and Hondralis, 2017). Thus, in line with role loss theory, East German mothers could experience a weaker effect on well-being through child leave, than West German mothers, as explained in the role loss section. 
Overall effect of child move on life satisfaction:

As previously described, role identity and role strain are two major channels that could explain why adult children leaving the parental home affects parental well-being. While the role identity channel predicts a negative impact of child leave on parental well-being, the role strain channel predicts a positive effect. Thus, based on theoretical considerations, the overall effect of child leave on well-being is still an open question. Figure 1 summarizes our key arguments.

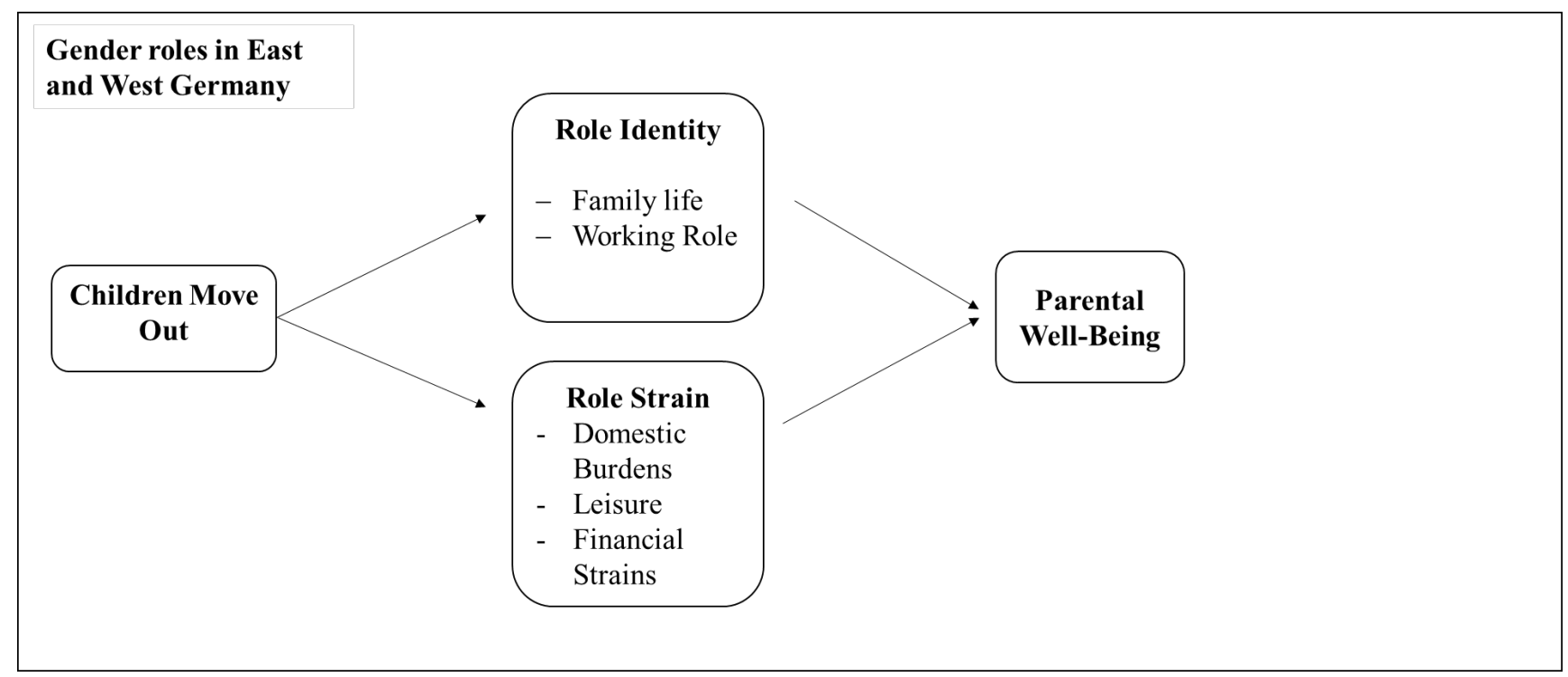

Figure 1: Theoretical overview

\section{Data and sample descriptives}

We use data from the German Socio-Economic Panel v33 (SOEP) in our analysis. We restrict our sample to the survey years 1991-2016 (because the SOEP started interviewing in East Germany from 1991 onwards) and to individuals aged 19 to 65 . The SOEP surveys all members in a household starting from the age of 16, which allows us to track respondents for a long period of time.

We keep all respondents in our sample who are parents. We define parents as respondents who report birth dates for their children or who report children in their household. Thus, in some 
cases, parents are not necessarily biological parents, but could also be step parents. Our regressor of interest is a variable which identifies whether an adult child has moved out of the parental household. In general, we identify children moving out if one of the following holds true: (i) if the child's household identifier changes, but not the parents', (ii) if the number of children aged 16 and above in the household declines, (iii) if there were children in the household in period $\mathrm{t}-1$, but none are left in $\mathrm{t}$, (iv) if parents report that a child has moved out and there have been children in the household in time t-1. Furthermore, for all of the above, we only identify moves if the parent is at least 35 years old at the time of moving (see Appendix B for a detailed description of the procedure). We make sure that the moves are not the outcome of parental separation by keeping the parents' household ID constant during the year of the move as well as by controlling for moves during the whole period investigated.

For our main analysis, we generate a variable that measures the time around children moving out, from 5 years prior to the move up to 10 years after the move. We focus on two types of moves in our main analysis: the first move of a child from the parental household as well as empty nest moves with no children left in the household after the move. We also keep parents that did not experience a child moving out during the survey period in order to disentangle the dynamics of the effect of a child moving out in our fixed effects models from general time trends which are measure with survey year and age dummies.

The SOEP includes a measure for self-assessed life satisfaction in every survey wave. Respondents are asked to rate their overall life satisfaction on a scale from 0 (poor) to 10 (very high). This is our main outcome of interest. Furthermore, we investigate several other outcomes to identify channels of the effect of child move on life satisfaction. These are (i) satisfaction with family life (self-assessed, 0-10), (ii) satisfaction with leisure time (self-assessed, 0-10), (iii) the number of hours spent in housework during a typical day in the work week and (iv) satisfaction with household finances (self-assessed, 0-10). 
Table 1 shows sample descriptives for parents separate by gender and type of move at the time of the respective move. The mean age at moving is around 50 for first moves and around 53 for empty nest moves. Furthermore, for the subset of births that we can track after moving out, the mean age of children at the time of moving is around 23. This is consistent with official statistics for Germany (Statista Research Department, 2020).

Table 1: Sample descriptives at time of moving

\begin{tabular}{|c|c|c|c|c|c|c|}
\hline & $(1)$ & $(2)$ & (3) & (4) & $(5)$ & (6) \\
\hline & \multicolumn{2}{|c|}{ All Moves } & \multicolumn{2}{|c|}{ First Moves } & \multicolumn{2}{|c|}{ Empty Nest } \\
\hline & Mother & Father & Mother & Father & Mother & Father \\
\hline Life satisfaction & 6.82 & 6.83 & 6.89 & 6.88 & 6.78 & 6.70 \\
\hline Age & 49.51 & 51.75 & 48.07 & 50.12 & 52.56 & 53.75 \\
\hline Years of schooling & 11.82 & 12.29 & 11.90 & 12.37 & 11.79 & 12.28 \\
\hline East Germany $(0 / 1)$ & 0.25 & 0.25 & 0.26 & 0.26 & 0.31 & 0.30 \\
\hline $\begin{array}{l}\text { In labor force }(0 / 1) \text {, } \\
1 \text { year lagged }\end{array}$ & 0.64 & 0.83 & 0.66 & 0.85 & 0.65 & 0.76 \\
\hline $\begin{array}{l}\text { Working full-time } \\
(0 / 1), 1 \text { year lagged }\end{array}$ & 0.34 & 0.81 & 0.34 & 0.83 & 0.40 & 0.74 \\
\hline Married $(0 / 1)$ & 0.74 & 0.84 & 0.73 & 0.82 & 0.73 & 0.78 \\
\hline $\begin{array}{l}\text { Still children in the } \\
\text { house }(0 / 1)\end{array}$ & 0.68 & 0.67 & 0.70 & 0.68 & 0.00 & 0.00 \\
\hline Number of children & 2.51 & 2.21 & 2.28 & 2.13 & 2.00 & 1.76 \\
\hline $\begin{array}{l}\text { Empty nest move } \\
(0 / 1)\end{array}$ & 0.29 & 0.29 & 0.24 & 0.26 & & \\
\hline Observations & 9883 & 8224 & 4666 & 3975 & 2819 & 2419 \\
\hline
\end{tabular}

We also use a number of control variables in our analysis: age, age squared, survey year dummies, years of schooling, and a dummy variable indicating whether the respondent moved since the last wave. We abstain from controlling for some other time-varying factors that are included in the data, like health satisfaction, because they could be potential mediators of the causal effect and would be "bad controls". However, we use some variables (specifically: time spent on housework, satisfaction with family life, satisfaction with the financial situation and leisure satisfaction) to investigate channels of the effect in a separate mediation analysis in which we calculate what share of the overall effect can be attributed to specific channels 


\section{Analytical Strategy}

Identifying the effect of adult children moving out on parental life satisfaction is potentially plagued by various endogeneity problems that could bias OLS estimates. For example, the children of unhappy parents could be more likely to move out. Thus, just comparing the mean life satisfaction of parents whose children moved out and whose children stayed likely results in biased estimates. To circumvent this problem, we use a fixed effects approach, therefore accounting for individual time-constant heterogeneity (Allison, 2009).

Specifically, we use dummy impact functions (Allison, 1994) to investigate the effect of children moving out on parental life satisfaction. In contrast to classical fixed effects estimates that would simply map the effect of a child moving out as a before/after-comparison identified through individuals that experience the event, this dynamic modelling framework enables us to identify the effect of children moving out for each year around the event. Specifically, we estimate the following regression model:

$$
\text { lifesat }_{i t}=\alpha_{i}+\gamma_{t}+\beta X_{i t}^{\prime}+\epsilon_{i t}
$$

where $\alpha_{i}$ are individual fixed effects, $\gamma_{t}$ are indicator variables that measure the time to the move of the child, $X_{i t}^{\prime}$ is a set of covariates (age, age ${ }^{2}$, marital status, survey year dummies and whether a move of the parent occurred) and $\epsilon_{i t}$ is an idiosyncratic error term. lifesat ${ }_{i t}$, the outcome, is parental life satisfaction.

The main parameter estimates of interest are $\gamma_{t}$ as they measure the response of parental life satisfaction to children moving out on a yearly basis. This approach allows us to evaluate whether the effect fades out over time (i.e. parents adapt to living without the child at home), or if it is a lasting effect. As the time around moving out is measured with dummy variables from 5 years prior to the child moving out to 10 years after, we have to choose an omitted category which serves as the reference point. We use the year prior to the child moving out as 
the omitted category to see whether life satisfaction changes compared to the state in which the child still lived in the household.

Furthermore, as we also include the years prior to children moving out, the model allows us to directly investigate potential problems with reverse causality. Arguably, parents becoming unhappy could result in adult children moving out. Thus, reverse causality could bias our estimates, even when using fixed effects (see Leszczensky and Wolbring, 2019). However, we can, at least on a yearly basis, simply see if this poses a problem by investigating the coefficients prior to children moving out: if these are significantly different from zero, there is potentially some source of bias.

Since we control for individual fixed effects in our analysis, we cannot solely use a sample of individuals that we observe around the time of children moving out to identify any effects. This is because age, survey year and the impact dummies are perfectly collinear in fixed effects models. When the time to the move changes, so does age and survey year and thus, the effect is not identified.

To circumvent this problem, we include parents whose children have already moved out as well as parents with younger children that do not move out during the time of the survey as a control group. We assign a fixed value for the impact dummy for this group that does not change. Thus, we can use this group to identify the effects of age and survey year dummies and are thus able to estimate coefficients for the impact dummies for the group that eventually experiences a child moving out. Thus, we are able to separate age, survey year and impact dummies by using parents who do not experience a move during the time of the survey as a control group. Appendix Table A1 presents descriptive statistics for the samples of ever treated and never treated parents.

Due to power issues, analyses of subsamples solely rely on classical fixed effects models with a binary variable indicating whether an adult child moved out as the regressor of interest. In 
these analyses, we base our estimates only on individuals that are ever treated, because, in contrast to the impact dummy function, a simple binary indicator for children leaving home still leaves variation to estimate age and survey year effects. Thus, we only rely on individuals that are treated at some point in these analyses as we consider them to be the natural control group. Like in the baseline models, we control for age and survey year fixed effects to account for trends in age and over time.

\section{Results}

\section{Which move matters?}

As previously discussed, large parts of the literature rely on simple linear regressions. Such cross-section OLS estimates of the effects of adult children leaving the parental home on life satisfaction (simply referred to as child leave hereafter) are likely biased due to selection und unobserved heterogeneity. Thus, we begin by estimating the overall impact of child leave with standard pooled OLS and FE models. As explained in the theory section, we estimate the model separately for the first and last child moving out to investigate whether parents experience abrupt change or a gradual process. As this coincides in some cases, we also estimate the effect for moves where the first move equals the last move (i.e. single children).

Table 2 shows the results of these regressions. As can be seen in column 1, OLS provides statistically significant, negative effects of child leave on parental life satisfaction. However, this changes when introducing fixed effects into the model in column 2: The coefficient of the first move halves in magnitude but remains statistically significant. Results are in line with the role identity channel which predicted a negative effect. In contrast, the impact of the empty nest move on parental life satisfaction is only about one sixth of the OLS models when introducing fixed effects and not significant anymore. 


\begin{tabular}{|c|c|c|}
\hline & $\begin{array}{l}\text { (1) } \\
\text { OLS }\end{array}$ & $\begin{array}{l}\text { (2) } \\
\mathrm{FE}\end{array}$ \\
\hline First Move & $\begin{array}{l}-0.189^{* * *} \\
(0.022)\end{array}$ & $\begin{array}{l}-0.081^{* * *} \\
(0.019)\end{array}$ \\
\hline $\mathrm{N}$ & 82109 & 82109 \\
\hline Number of individuals & 11571 & 11571 \\
\hline Empty Nest Move & $\begin{array}{l}-0.185^{* * *} \\
(0.034)\end{array}$ & $\begin{array}{l}-0.031 \\
(0.026)\end{array}$ \\
\hline $\mathrm{N}$ & 33609 & 33609 \\
\hline Number of individuals & 3530 & 3530 \\
\hline First Move, not empty Nest & $\begin{array}{l}-0.194^{* * * *} \\
(0.024)\end{array}$ & $\begin{array}{l}-0.064^{* *} \\
(0.021)\end{array}$ \\
\hline $\mathrm{N}$ & 69203 & 69203 \\
\hline Number of individuals & 10125 & 10125 \\
\hline Last move, not first & $\begin{array}{l}-0.135^{* *} \\
(0.046)\end{array}$ & $\begin{array}{l}0.035 \\
(0.033)\end{array}$ \\
\hline$N$ & 20703 & 20703 \\
\hline Number of individuals & 2084 & 2084 \\
\hline First Move that are Empty Nest Moves & $\begin{array}{l}-0.220^{* * *} \\
(0.055)\end{array}$ & $\begin{array}{l}-0.132^{* *} \\
(0.045)\end{array}$ \\
\hline$N$ & 12906 & 12906 \\
\hline Number of individuals & 1146 & 1146 \\
\hline
\end{tabular}

Controls: age, age squared, survey year dummies, years of schooling, move (0/1) Standard errors in parentheses. Significance levels: ${ }^{*} p<0.05,{ }^{* *} p<0.01,{ }^{* * *} p<0.001$

In a next step, we investigate first moves that are not empty nest moves. Again, we find significantly negative correlations in this case in both OLS and FE in the same magnitude as the overall first move effect. Looking just as empty nest moves that are not first moves again shows no statistically significant correlation with parental well-being when using FE. Both coefficients differ significantly from each other $(|Z|=2.54$, $p$-val $=0.01)$, indicating that it is indeed the first move that matters for parental well-being.

When first child move coincides with the empty nest move, i.e. a single child is moving out, the effect remains statistically significant and negative. The size of this single child move effect 
is about twice as large as of other first moves highlighting the closer relationship between parents and child in such single-child families.

Overall, the results show that using OLS results in biased estimates of the impact of adult children leaving the parental home on parental life satisfaction. As discussed, the bias in OLS can be driven by time-constant differences in gender norms and selection based on timeinvariant levels of parental well-being. Thus, the remainder of our analysis relies on FE models. Our findings also show that the type of move (first or last) is important, which implies that it is problematic to simply compare average life satisfaction levels of parents with and without resident children.

\section{Dynamics of the move effects}

In this section, we apply dummy impact functions to investigate the effect of adult children leaving the parental home on life satisfaction over time. As discussed in Section 2, it is a priori unclear whether parental well-being reacts to the launching phase, when they gain the first experiences with a child out of the parental home, and/or to the empty nest period, when there are no children left. 


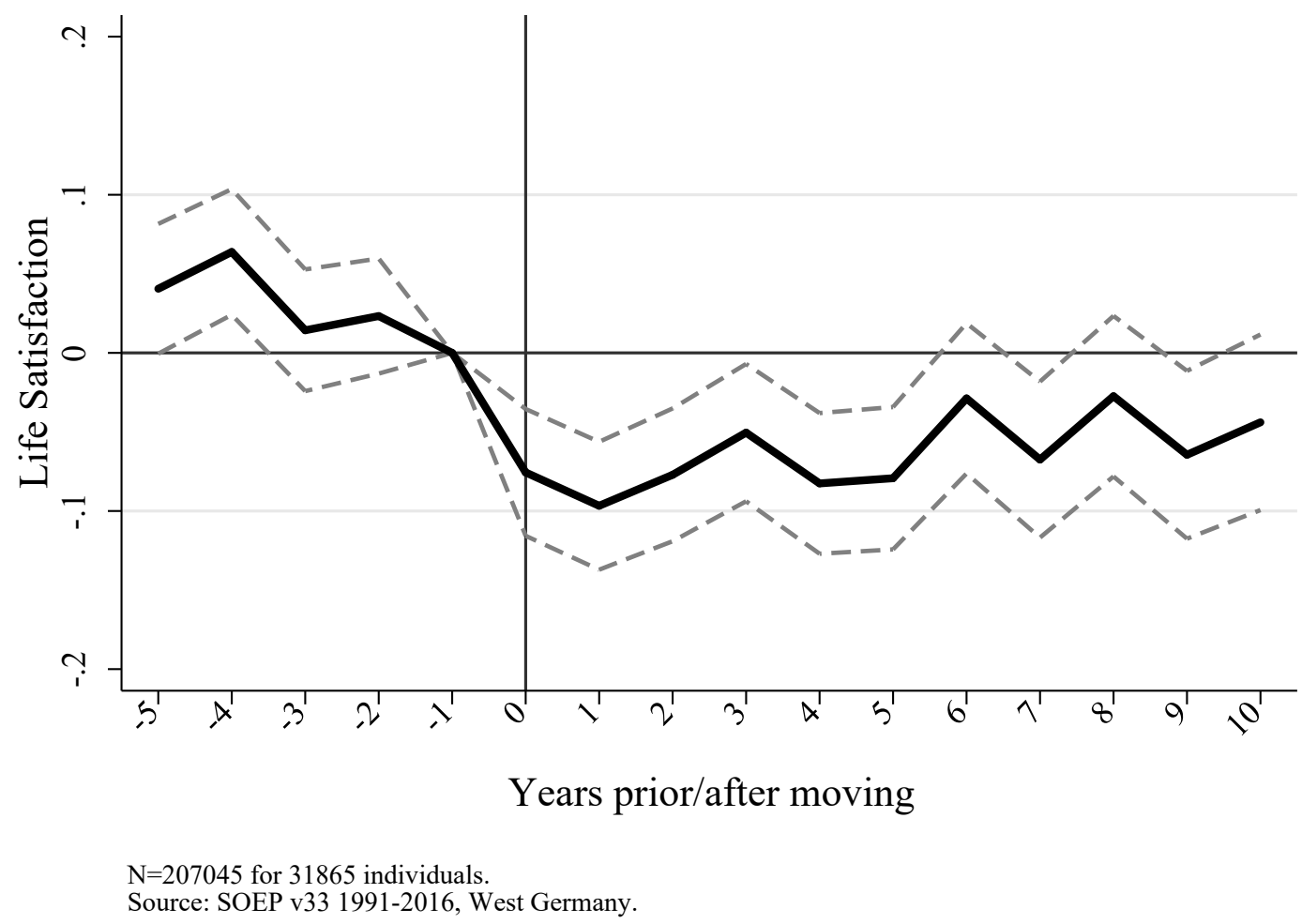

Figure 2: The impact of the launching phase on parental life satisfaction (controls as in Table 2, corresponding coefficients are displayed in Appendix Table A2).

We begin by investigating the launching period. Figure 2 shows the results of the impact dummy function with $95 \%$ confidence intervals, conditional on age, age ${ }^{2}$, survey year dummies, and an indicator variable that measures whether the parents moved in year t. Appendix Table A2 shows the coefficients for the impact dummies corresponding to Figures 2 to 5 . As can be seen, the results reveal a significant decrease in parental life satisfaction due to the launching phase, thereby supporting Hypothesis 1 , in contrast to the increase in life satisfaction presumed in Hypothesis 2. This decrease in life satisfaction remains relatively constant, although it is statistically indistinguishable from 0 on the $5 \%$-level in several years after children moving out. Nevertheless, the point estimates, even in these cases, do not differ significantly from the drop shortly after moving out. Thus, this suggests a relatively constant effect. Furthermore, there is no significant time trend prior to the treatment year (although the coefficient of the fourth year 
prior to moving differs significantly from the reference year), thus suggesting the absence of reverse causality.

Next, we investigate the empty nest period in Figure 3. Interestingly, our results show no significant impact of the empty nest period on parental life satisfaction. Even though the estimates are relatively noisy, the point estimates are close to zero, with the exception of year 9 after moving out. Again, we find no evidence for a pre-treatment trend, supporting the validity of our analytical approach.

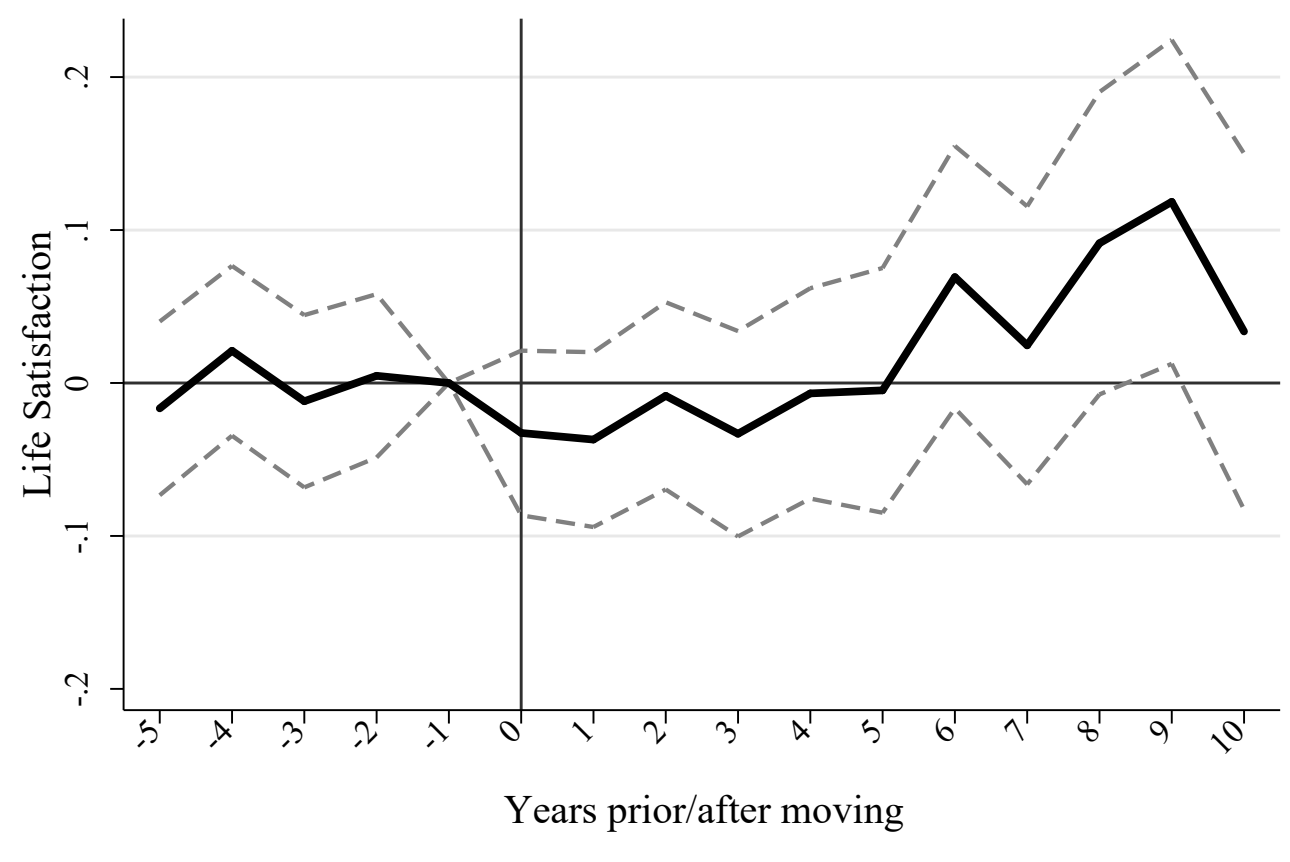

$\mathrm{N}=203101$ for 30833 individuals

Figure 3: The impact of the empty nest period on parental life satisfaction (controls as in Table 2, corresponding coefficients are displayed in Appendix Table A2).

Overall, our empirical analyses find strong evidence for a negative effect of the launching phase in support of Hypothesis 1, but no clear evidence for empty nest moves. In the big picture, the effects of role strain do not seem to outweigh the impact induced by the shifting parental role. In the next steps, we dive into subgroup analyses and potential channels of the effect to gain a better understanding of the mechanisms at work. 


\section{Differences between mothers and fathers}

Next, we analyze whether mothers and fathers react differently to adult children moving out. We begin by investigating the impact of the launching phase. Figure 4 shows the dummy impact functions for mothers and fathers separately. Compared to the baseline analysis shown in Figure 2, the confidence bands increase due to the reduced power in analyses based on subsamples. Overall, the results suggest no significant differences in the reaction of mothers and fathers to the event.
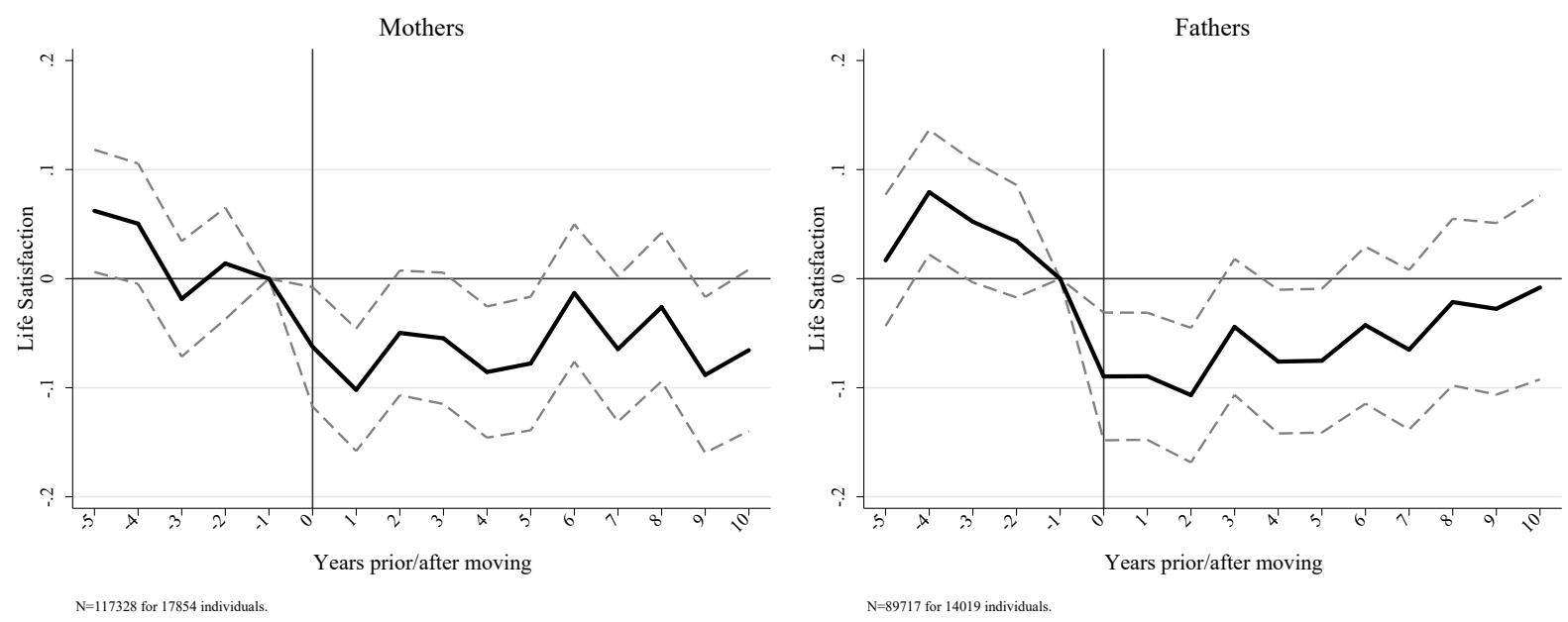

Source: SOEP v33 1991-2016, West Germany.

Figure 4: Separate event study regressions for the impact of the launching phase on parental life satisfaction by gender (controls as in Table 2, corresponding coefficients are displayed in Appendix Table A2).

Figure 5 displays the results of gender-specific models for the empty nest period. Like in the analysis with the pooled sample, there is no statistically significant impact of the empty nest move on mothers' life satisfaction. This is the case for fathers as well, although the results show a slight drop and subsequent increase in life satisfaction over time. However, a joint F-test for the period after the children moving out rejects the notion of a joint impact of the years after the empty nest move on fathers' life satisfaction $(F(11,13086)=1.45$; $p$-value: 0.14$)$. We thus 
conclude that neither for mothers nor for fathers there is a significant effect of the transition into the empty nest period on life satisfaction.
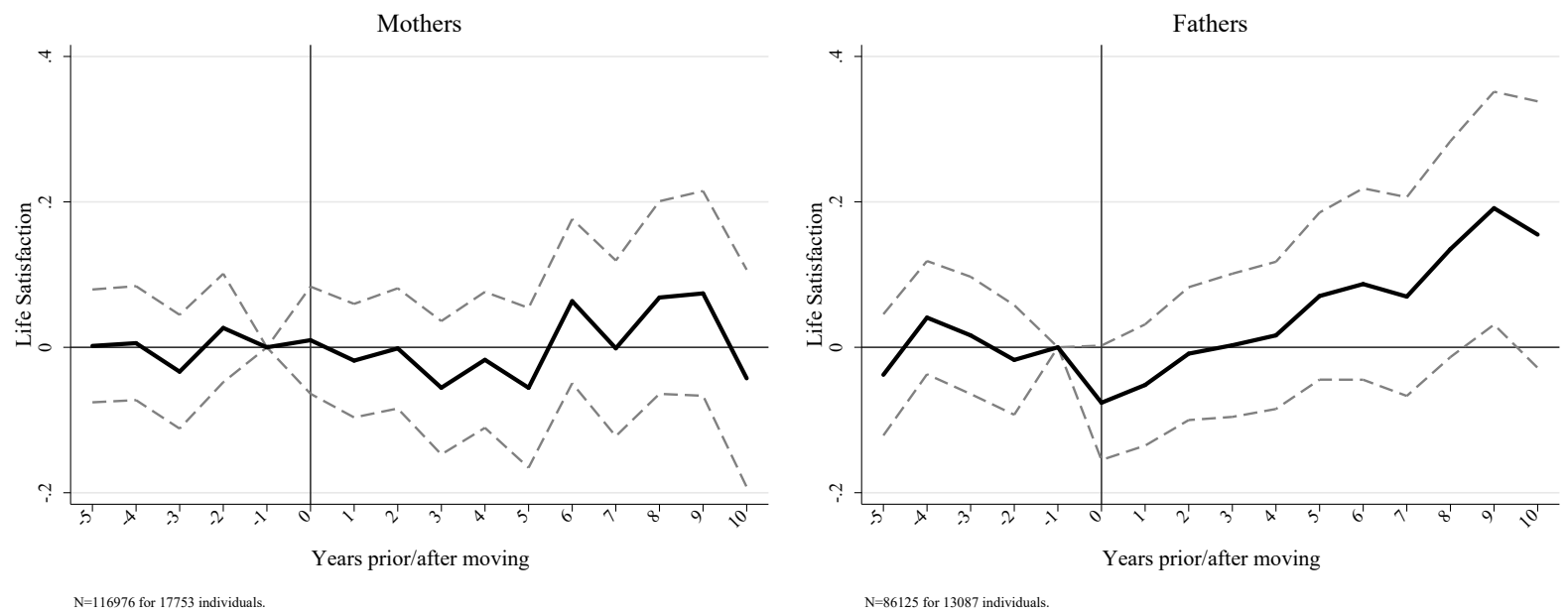

Source: SOEP v33 1991-2016, West Germany.

Figure 5: Separate event study regressions for the impact of the empty nest period on parental life satisfaction by gender (controls as in Table 2, corresponding coefficients are displayed in Appendix Table A2).

\section{Differences between East and West Germany}

Previously, we hypothesized that the effect of children moving out on life satisfaction is smaller for mothers in East Germany due to more egalitarian gender norms and a broader availability of early childcare institutions that could have long-lasting effects on the maternal role. Figure 6 shows the impact dummy function for East Germany by gender for the launching phase. 

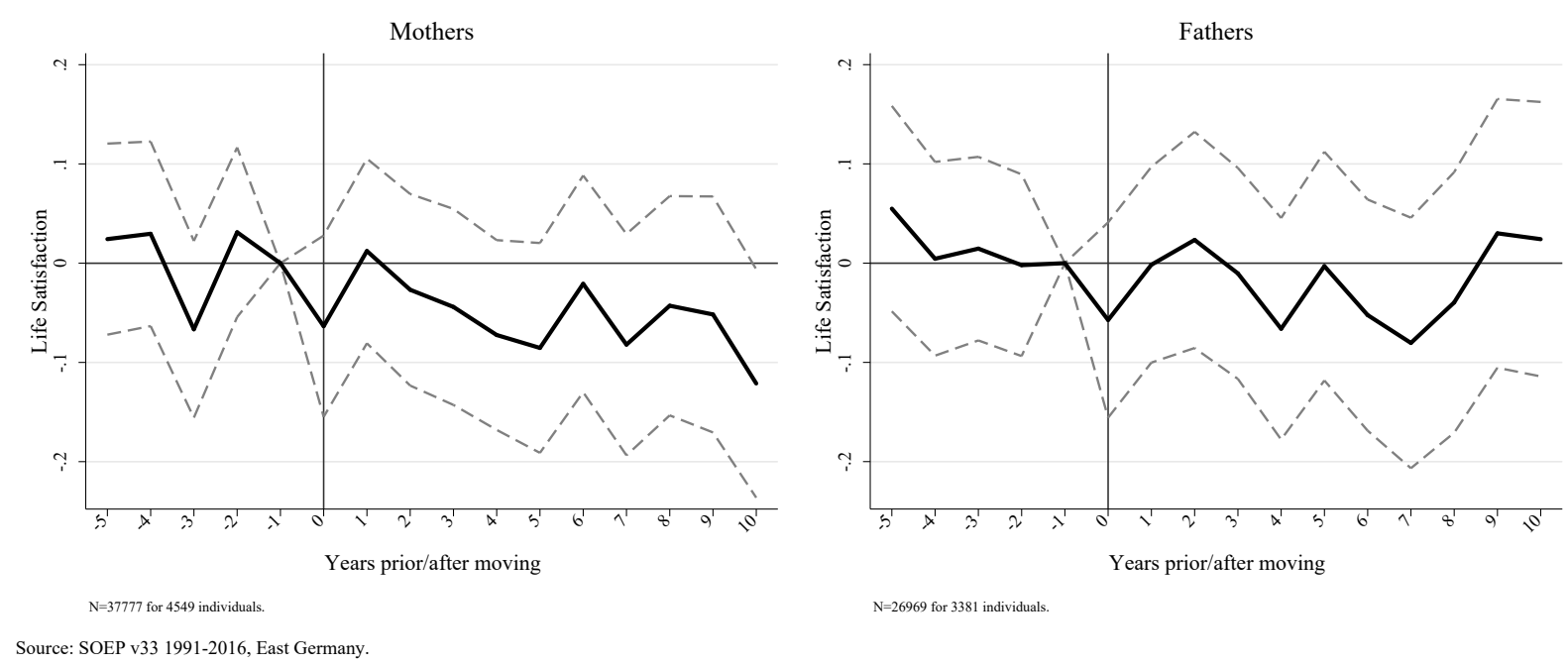

Figure 6: Separate event study regressions for the impact of the launching period on parental life satisfaction in East Germany (controls as in Table 2, corresponding coefficients are displayed in Appendix Table A2).

As can be seen, there is no statistically significant correlation between parental life satisfaction and the launching phase in East Germany for neither mothers nor fathers, in contrast to the results previously discussed for West Germany. This finding supports the theorized persistent differences in parental roles between East and West Germany. We also investigated whether there is a significant empty nest effect in East Germany, and also find none (results available upon request). Thus, our results do not support any significant impact of adult children moving out on parental life satisfaction in East Germany, thereby demonstrating the importance of the societal context in phenomena such as the empty nest effect. As we do not find significant effects (neither statistically nor in terms of magnitude) and lack statistical power due to a small number of observations in East Germany, we focus on West Germany in the remaining analysis.

\section{Employment-related Differences by Gender}

From this part of our analysis onwards, we rely on classical fixed effects models, as the sample sizes of some subgroups are too small to use dummy impact functions. In the next step, we investigate whether the effects of the launching phase differ by parental employment status and gender, based on theoretical considerations. The role strain channel predicts that two roles that 
are in conflict cause stress. The relief of one of these roles, e.g. the decreasing burden of being a mother when adult children move out, should therefore increase life satisfaction especially for working mothers, where there could be a conflict between the role as an employee and as a mother. In contrast, according to the role identity channel, the negative impact of the launching phase on life satisfaction is expected to be especially large for non-working mothers, as their role as mothers is particular affected by the absence of the child from home.

Table 3: Regression by parents' gender and employment status.

\begin{tabular}{lcc}
\hline & $\begin{array}{c}(1) \\
\text { Non-working }\end{array}$ & $\begin{array}{c}(2) \\
\text { Working }\end{array}$ \\
\hline (A) Mothers & $-0.095^{*}$ & -0.046 \\
& $(0.048)$ & $(0.035)$ \\
$\mathrm{N}$ & 12707 & 21662 \\
Number of individuals & 1660 & 2580 \\
\hline (B) Fathers & -0.038 & $-0.140^{* * *}$ \\
& $(0.099)$ & $(0.030)$ \\
& & \\
$\mathrm{N}$ & 3942 & 25960 \\
Number of individuals & 626 & 3174 \\
\hline \multicolumn{2}{c}{ Standard errors in parentheses. Controls as in Table 2.} \\
Significance levels: ${ }^{*} p<0.05,{ }^{* *} p<0.01,{ }^{* * *} p<0.001$
\end{tabular}

Table 3, Panel A shows the results of the launching phase on mothers' life satisfaction by employment status, measured one year prior to the child moving out. We use this definition of employment in order to prevent our results from being biased in cases employment status changes due to the child move. The results for mothers are overall in line with the role identity channel: the effect is negative and larger in magnitude for non-working mothers, whereas it does not significantly differ from zero for working mothers, i.e. for mothers who possess an additional role, thus supporting Hypothesis 1.

Table 3, Panel B shows the results for fathers. We find a highly significant, negative impact for working fathers, while the effect for non-working fathers is closer to zero in magnitude and 
statistically insignificant. This finding is surprising but supports the notion that working fathers could regret that they did not spend enough time with their children before they left. However the difference between working and non-working fathers should be interpreted with caution: non-working fathers in our data are a small, highly selective group, whereas working fathers follow their standard societal roles in a conservative male-breadwinner society in West Germany. The norm for fathers in West Germany is to work. Non-working fathers are a small subsample that also reports e.g. a low self-rated health (only 5.5 points on the $0-10$ scale), are older that the average (55 years) and report below-average education (11 years versus 12.26 for working fathers). We would like to note that, in the cases of non-working fathers and working mothers, we do not only reject effects due to a small sample size and thus insufficient statistical power, but also because the effects for both groups are relatively close to zero in magnitude.

\section{Mechanisms}

Next, informed by theory, we investigate potential mechanisms which bring about the moving effect on subjective well-being. While the overall effect of child leave seems to be driven by issues concerning parental roles, there is still room for the relief of burdens in some areas. The role strain theory implies that a decrease in stressful factors should positively affect parental life satisfaction and that child leave increases overall satisfaction with family life. Namely, we hypothesized that three dimensions could play a role: (i) a decrease in stressful interactions in the family, (ii) a decrease in daily demands and (iii) a decrease in financial burdens.

We operationalize these potential subdomains of role strain using four measures as outcomes in FE regressions: (i) overall satisfaction with family life, (ii) average daily time spent on housework (in hours), (iii) overall satisfaction with one's leisure time, and (iv) satisfaction with household income. Thereby, our mediation analysis rests on a bottom-up model of life satisfaction assuming that overall life satisfaction is the result of domain-specific satisfaction 
(for a discussion of the bottom-up and top-down model of well-being (see Scherpenzeel and Saris, 1996).

Table 4: Mediation analysis

\begin{tabular}{|c|c|c|c|c|}
\hline & & Mediator (M) & & \\
\hline & $\begin{array}{c}(1) \\
\text { Family } \\
\text { satisfaction }\end{array}$ & $\begin{array}{c}(2) \\
\text { Time spent on } \\
\text { housework }\end{array}$ & $\begin{array}{c}(3) \\
\text { Leisure } \\
\text { satisfaction }\end{array}$ & $\begin{array}{c}\text { (4) } \\
\text { Income } \\
\text { satisfaction }\end{array}$ \\
\hline $\begin{array}{l}\text { Total effect } \\
(\mathrm{X} \rightarrow \mathrm{Y})\end{array}$ & $\begin{array}{c}-0.099^{* * *} \\
(0.029)\end{array}$ & $\begin{array}{c}-0.078^{* * *} \\
(0.020)\end{array}$ & $\begin{array}{l}-0.085^{* * *} \\
(0.020)\end{array}$ & $\begin{array}{c}-0.080^{* * *} \\
(0.019)\end{array}$ \\
\hline$X \rightarrow M$ & $\begin{array}{c}-0.113^{* * *} \\
(0.034)\end{array}$ & $\begin{array}{l}-0.026 \\
(0.017)\end{array}$ & $\begin{array}{c}0.009 \\
(0.025)\end{array}$ & $\begin{array}{l}-0.122^{* * *} \\
(0.023)\end{array}$ \\
\hline $\mathrm{M} \rightarrow \mathrm{Y}$ & $\begin{array}{c}0.242^{* * *} \\
(0.008)\end{array}$ & $\begin{array}{c}-0.023^{* * *} \\
(0.007)\end{array}$ & $\begin{array}{l}0.128^{* * *} \\
(0.004)\end{array}$ & $\begin{array}{l}0.253^{* * *} \\
(0.004)\end{array}$ \\
\hline $\begin{array}{l}\text { Effect net of } M \\
(X \rightarrow Y \mid M)\end{array}$ & $\begin{array}{c}-0.078^{* * *} \\
(0.020)\end{array}$ & $\begin{array}{c}-0.079^{* * *} \\
(0.020)\end{array}$ & $\begin{array}{c}-0.087^{* * *} \\
(0.019)\end{array}$ & $\begin{array}{c}-0.049^{* *} \\
(0.018)\end{array}$ \\
\hline Sobel T-stat & 2.087 & 2.824 & 3.113 & 2.287 \\
\hline Sobel p-value & 0.037 & 0.005 & 0.002 & 0.022 \\
\hline $\begin{array}{l}\text { Share of total effect explained } \\
\text { by M }\end{array}$ & $28 \%$ & $-1 \%$ & $-1 \%$ & $39 \%$ \\
\hline $\mathrm{N}$ & 35069 & 79087 & 78483 & 81537 \\
\hline
\end{tabular}

To estimate the impact of these mediators and investigate whether they are significant drivers of the overall effect, we investigate the effect of children leaving the parental home $(\mathrm{X})$ on parental life satisfaction $(\mathrm{Y})$ with and without controlling for the respective mediators $(\mathrm{M})$, as well as the impact of children leaving the parental home on the mediators. If $\mathrm{X}$ affects $\mathrm{M}$ and $\mathrm{M}$ affects $\mathrm{Y}$ significantly, we conclude that the respective variable might be an important mediator of the effect. Further, we also calculate the relative contribution of the respective mediator to the total effect and investigate its statistical significance via a Sobel-test (Sobel, 1982). While mediation analysis thereby assumes causal ordering of $\mathrm{X}, \mathrm{M}$, and $\mathrm{Y}$, a cautionary interpretation is warranted. First, some of the mediators might be endogenous or might correlate with other unobserved time-varying variables. Second, the fact that both overall and domainspecific satisfaction are subjective measures causes a common methods bias which likely leads 
to an overestimation of the amount of "explained" variance. Nonetheless, such a mediation analysis can provide important insights into processes at work.

Table 4 shows the results. Note that sample sizes across models differ, as there may be missing values in the respective mediator. Thus, we also show the total effect for each subsample (under total effect). Overall, the effects across subsamples are very similar. Additionally, Appendix Table A3 shows the effects of $\mathrm{X}$ on $\mathrm{M}$ by gender to investigate heterogeneous effects for mothers and fathers. Because there are hardly any differences, we rely on pooled estimations in this analysis for simplicity.

First, we investigate the effect of children moving out on the mediator ( $X$ to $M)$. We begin by investigating potential effects on family satisfaction. We observe a statistically significant reduction in the satisfaction with family life (Table 4, column 1). It could be the case that parents may miss children at the parental home and may regret spending not enough time with them, especially fathers (Sheriff and Weatherall, 2009).

Second, we investigate the role of household burdens, specifically the spent on housework (Table 4, column 2). Interestingly, on average, there is no overall effect of children moving out on time spent on housework. However, investigating the effect separately by gender (Appendix Table A3), we find that children moving out increases fathers' time spent on housework by around 15 minutes per day and decreases the time spent on housework for mothers around the same magnitude. Satisfaction with leisure time, another measure that is likely to capture changes in household burdens, in contrast, is not affected by children moving out (Table 4, column 3).

Third, financial strains due to children are potentially important. Satisfaction with household income decreases for parents after the move (Table 4, column 4). Potentially, as this is the launching phase, children still need financial support after they have moved out which could be more costly for parents compared to them living at the parental home. The literature shows that 
parental happiness could be comprised by financial strains (Pollmann-Schult, 2014). In our sample, $25 \%$ of the identified children do not work in the year after the move (because they are e.g. studying). $46 \%$ of children moving out report that they have received a private income transfer (thus, likely from parents) of, on average, EUR 4800 in the year of moving out. Thus, children that have already moved out still frequently pose a substantial burden on parents' household finances.

Next, we estimate a formal Sobel test (Baron and Kenny, 1986, Sobel, 1982) for mediation analysis, displayed in the lower part of Table 4. In these analyses, we first estimate the impact of children on parental life satisfaction for the subsample with complete information on the mediator. In the next step, we estimate a model that additionally controls for the potential channel, which allows us to calculate the Sobel t-statistic and thus investigate whether there is a significant mediating effect. Intuitively, this test allows us to examine which share of the total effect of the first child moving out is explained by a given mediator. ${ }^{1}$ Furthermore, we calculate the relative reduction of the coefficient for children between the two models to investigate what share of the overall effect is "explained" by the respective channel.

Overall, especially income satisfaction and satisfaction with family life can "explain" relatively large shares of the overall effect (38\% and $28 \%$, respectively). Housework and satisfaction with leisure time, in contrast, hardly "explain" the effect. Thus, about one third of the effect of children moving out on life satisfaction works through changes in the satisfaction with family life or satisfaction with the household income, respectively.

\section{Conclusion and Discussion}

Children leaving the parental home is an important life event not only for children, but also for their parents. Various studies investigate the impact of child leave on parental well-being, with

\footnotetext{
${ }^{1}$ Note that we do not show separate analyses by gender for simplicity, as the results regarding the mediation analysis did not differ.
} 
a special focus on empty nest moves and mixed results. In this paper we take a step back and investigate how children's departure from parental home in general affects parental well-being. We distinguish between the first move and the empty nest move. Based on the role identity and the role strain channel, we argue that the impact of child leave on parental well-being is an open empirical question.

Overall, our results reveal a negative impact of child leave on parental well-being for mothers and fathers. Although we find evidence for role strain relief in housework for females, the role identity channel seems to outweigh the positive effect of child leave on parental life satisfaction. In general, we find that parents who follow traditional gender roles (i.e. non-working mothers and working fathers) are hit hardest in terms of life satisfaction. Mothers without the additional role of an employee experience a drop in well-being, which points toward the role identity channel that goes along with a decrease in well-being. In contrast, fathers who are employed also experience a drop in life satisfaction. We find no negative impact of child leave on parental well-being for East German mothers or fathers supporting the notion of societal differences in gender roles.

While past research has mainly focused on the empty nest, our results reveal that especially the first move is important and triggers a gradual process which finally leads to an empty nest. Differentiating between the first move and the empty nest move, we show that the first move decreases parental well-being whereas the empty nest move does not further affect parental well-being. The special case that the first move and the empty nest move are the same - that is single children leaving home - has especially strong effects on parental well-being.

We would also like to point to some limitations of our analysis. First, as in all analyses using observational data reverse causality could pose a problem: do children moving out affect parental well-being or vice versa? While we cannot completely rule out biases due to reverse causality, the dummy impact functions with lags and leads provide the opportunity to detect 
some forms of endogenous selection into child move. Our analyses show that there is no significant pre-trend in parental life satisfaction prior to children moving out. However, reverse causality could still be a problem in the short run (if it occurs between two survey waves).

Second, due to limited sample sizes or lack of adequate indicators we did not further investigate potential effect heterogeneity by subgroups. This particularly concerns variables such as age at moving, reasons for moving out, frequency of social interactions between parents and child after the move and geographical distance of the child's old and new home. For the same reasons, we were unfortunately unable to investigate the dynamics of the effects using impact dummies and mediating effects for subgroups, although theory would suggests that different mechanisms might be at work for different subgroups.

Finally, while we conduct a formal mediation analyses and find suggestive evidence for especially satisfaction with family life and financial constraints to be important channels, this provides no rigorous test of causal mechanisms. It could be the case that these variables correlate with unobservables and thus provide no real causal explanation. However, the mediation analyses, at the very least, point to important factors through which causal explanations could occur.

In light of these limitations, our study also provides directions for future research. In particular, it would be interesting to further investigate the aforementioned heterogeneities, e.g. whether effects differ by children's distance to the parental home or by contact frequency after moving out, questions that are beyond the scope of our paper. Future research could also provide further evidence on other countries as our analyses show that the cultural context matters. Using existing indicators to what degree countries still follow a traditional male breadwinner model or a more egalitarian approach, could be a fruitful avenue to further study how the effects of child mover differ across societies. 


\section{References}

1. Allison, P.D., 1994. Using panel data to estimate the effects of events. Sociological Methods \& Research 23, 174-199.

2. Allison, P.D., 2009. Fixed effects regression models. SAGE publications, Thousand Oaks.

3. Anderson, S.A., Russell, C.S., Schumm, W.R., 1983. Perceived Marital Quality and Family LifeCycle Categories: A Further Analysis. Journal of Marriage and Family 45, 127-139.

4. Back, K.W., 1971. Transition to aging and the self-image. Aging and Human Development 2, 296-304.

5. Barber, C.E., 1989. Transition to the Empty Nest. In: Bahr, S. J., and Peterson, E. T., (Eds.), Aging and the Family. Lexington Books, Lexington (Massachusetts), pp. 15-32.

6. Barnett, R.C., Baruch, G.K., 1985. Women's involvement in multiple roles and psychological distress. Journal of Personality and Social Psychology 49, 135.

7. Baron, R.M., Kenny, D.A., 1986. The moderator-mediator variable distinction in social psychological research: Conceptual, strategic, and statistical considerations. Journal of personality and social psychology 51, 1173.

8. Bauernschuster, S., Rainer, H., 2012. Political regimes and the family: how sex-role attitudes continue to differ in reunified Germany. Journal of Population Economics 25, 5-27.

9. Becker, C., Kirchmaier, I., Trautmann, S.T., 2019. Marriage, parenthood and social network: Subjective well-being and mental health in old age. PloS one 14.

10. Borland, D.C., 1982. A Cohort Analysis Approach to the Empty-Nest Syndrome among Three Ethnic Groups of Women: A Theoretical Position. Journal of Marriage and Family 44, 117-129.

11. Bouchard, G., 2014. How Do Parents React When Their Children Leave Home? An Integrative Review. Journal of Adult Development 21, 69-79.

12. Caputo, J., 2019. Crowded nests: parent-adult child coresidence transitions and parental mental health following the great recession. Journal of health and social behavior 60, 204-221.

13. Danziger, S., Ratner, D., 2010. Labor market outcomes and the transition to adulthood. The Future of Children, 133-158.

14. Durkheim, E., 1951. Suicide. Glencoe. Free Press.

15. Erickson, J.J., Martinengo, G., Hill, E.J., 2010. Putting work and family experiences in context: Differences by family life stage. Human Relations 63, 955-979.

16. Fingerman, K.L., Cheng, Y.P., Wesselmann, E.D., Zarit, S., Furstenberg, F., Birditt, K.S., 2012. Helicopter parents and landing pad kids: Intense parental support of grown children. Journal of Marriage and Family 74, 880-896.

17. Glenn, N.D., 1975. Psychological well-being in the postparental stage: Some evidence from national surveys. Journal of Marriage and the Family 37, 105-110.

18. Glenn, N.D., McLanahan, S., 1982. Children and Marital Happiness: A Further Specificiation of the Relationship. Journal of Marriage and Family 44, 63-72.

19. Gorchoff, S.M., John, O.P., Helson, R., 2008. Contextualizing Change in Marital Satisfaction During Middle Age. Psychological Science 19, 1194-1200.

20. Graham, C., 2011. Adaptation amidst prosperity and adversity: Insights from happiness studies from around the world. The World Bank Research Observer 26, 105-137.

21. Grunow, D., Begall, K., Buchler, S., 2018. Gender Ideologies in Europe: A Multidimensional Framework. J Marriage Fam 80, 42-60.

22. Grzywacz, J.G., Almeida, D.M., McDonald, D.A., 2002. Work-Family Spillover and Daily Reports of Work and Family Stress in the Adult Labor Force. Family Relations 51, 28-36.

23. Gunderson, J., Barrett, A.E., 2017. Emotional cost of emotional support? The association between intensive mothering and psychological well-being in midlife. Journal of Family Issues 38, 992-1009.

24. Hansen, T., 2012. Parenthood and Happiness: a Review of Folk Theories Versus Empirical Evidence. Social Indicators Research 108, 29-64. 
25. Harkins, E.B., 1978. Effects of Empty Nest Transition on Self-Report of Psychological and Physical Well-Being. Journal of Marriage and Family 40, 549-556.

26. Knoester, C., 2003. Transitions in Young Adulthood and the Relationship between Parent and Offspring Well-Being. Social Forces 81, 1431-1458.

27. Leszczensky, L., Wolbring, T., 2019. How to deal with reverse causality using panel data? Recommendations for researchers based on a simulation study. Sociological Methods \& Research.

28. Lucas, R.E., Clark, A.E., 2006. Do people really adapt to marriage? Journal of happiness studies 7, 405-426.

29. Marks, S.R., 1977. Multiple Roles and Role Strain: Some Notes on Human Energy, Time and Commitment. American Sociological Review 42, 921-936.

30. Mead, G.H., 1934. Mind, Self and Society. The University of Chicago Press, Chicago.

31. Merz, J., 2018. Are retirees more satisfied?-Anticipation and adaptation effects of retirement on subjective well-being: A panel analysis for Germany. SOEPpaper.

32. Milkie, M.A., Nomaguchi, K., Schieman, S., 2019. Time deficits with children: The link to parents' mental and physical health. Society and Mental Health 9, 277-295.

33. Mitchell, B.A., Lovegreen, L.D., 2009. The Empty Nest Syndrome in Midlife Families. A Multimethod Exploration of Parental Gender Differences and Cultural Dynamics. Journal of Family Issues 30, 1651-1670.

34. Musick, K., Meier, A., Flood, S., 2016. How parents fare: Mothers' and fathers' subjective wellbeing in time with children. American Sociological Review 81, 1069-1095.

35. Nomaguchi, K., 2012. Parenthood and psychological well-being: Clarifying the role of child age and parent-child relationship quality. Social science research 41, 489-498.

36. Nomaguchi, K., Milkie, M.A., 2020. Parenthood and well-being: A decade in review. Journal of Marriage and Family 82, 198-223.

37. Pearlin, L.I., 1989. The sociological study of stress. Journal of health and social behavior, 241256.

38. Pfau-Effinger, B., Geissler, B., 2002. Cultural Change and Family Policies in East and West Germany. In: Carling, A., Duncan, S., and Edward, R., (Eds.), Analysing Families: Morality and Rationality in Policy and Practice. Routledge, New York.

39. Pollmann-Schult, M., 2014. Parenthood and life satisfaction: Why don't children make people happy? Journal of Marriage and Family 76, 319-336.

40. Raup, J.L., Myers, J.E., 1989. The Empty Nest Syndrome: Myth or Reality? Journal of Counseling and Development 68, 180-183.

41. Reczek, C., Zhang, Z., 2016. Parent-child relationships and parent psychological distress: How do social support, strain, dissatisfaction, and equity matter? Research on aging 38, 742-766.

42. Reed, K., Duncan, J.M., Lucier-Greer, M., Fixelle, C., Ferraro, A.J., 2016. Helicopter parenting and emerging adult self-efficacy: Implications for mental and physical health. Journal of Child and family Studies 25, 3136-3149.

43. Ridgeway, C.L., Correll, S.J., 2004. Unpacking the Gender System. Gender \& Society 18, 510531.

44. Rosenfeld, R.A., Trappe, H., Gornick, J.C., 2004. Gender and work in Germany: Before and after reunification. Annu. Rev. Sociol. 30, 103-124.

45. Scherpenzeel, A., Saris, W., 1996. Causal direction in a model of life satisfaction: The topdown/bottom-up controversy. Social Indicators Research 38, 161-180.

46. Schober, P.S., Spiess, C.K., 2015. Local day care quality and maternal employment: evidence from East and West Germany. Journal of Marriage and Family 77, 712-729.

47. Scott, J., Alwin, D.F., 1989. Gender differences in parental strain: Parental role or gender role? Journal of Family Issues 10, 482-503.

48. Seiffe-Krenke, I., 2006. Leaving home or still in the nest? Parent-child relationships and psychological health as predictors of different leaving home patterns. Developmental psychology $42,864$. 
49. Sheriff, M., Weatherall, A., 2009. A Feminist Discourse Analysis of Popular-Press Accounts of Postmaternity. Feminism \& Psychology 19, 89-108.

50. Sieber, S.D., 1974. Toward a Theory of Role Accumulation. American Sociological Review 39.

51. Sobel, M.E., 1982. Asymptotic confidence intervals for indirect effects in structural equation models. Sociological methodology 13, 290-312.

52. Statista Research Department, 2020. Durchschnittliches Alter beim Auszug aus dem Elternhaus in Ländern Europas 2019.

53. Stryker, S., 2002. Traditional Symbolic Interactionism, Role Theory, and Structural Symbolic Interactionism. The Road to Identity Theory. In: Turner, J. H., (Ed., Handbook of Sociological Theory. Springer US, New York, pp. 211-231.

54. Stryker, S., Serpe, R.T., 1982. Commitment, identity salience, and role behavior: Theory and research example, Personality, roles, and social behavior. Springer, pp. 199-218.

55. Switek, M., Easterlin, R.A., 2018. Life transitions and life satisfaction during young adulthood. Journal of Happiness Studies 19, 297-314.

56. Thoits, P.A., 1983. Multiple Identities and Psychological Well-Being: A Reformulation and Test of the Social Isolation Hypothesis. American Sociological Review 48, 174-187.

57. Thoits, P.A., 1991. On merging identity theory and stress research. Social psychology quarterly, 101-112.

58. Tosi, M., 2020. Boomerang Kids and Parents' Well-Being: Adaptation, Stressors, and Social Norms. European Sociological Review.

59. Tosi, M., Grundy, E., 2018. Returns home by children and changes in parents' well-being in Europe. Social Science \& Medicine 200, 99-106.

60. Twenge, J.M., Campbell, W.K., Foster, C.A., 2003. Parenthood and Marital Satisfaction: A MetaAnalytic Review. Journal of Marriage and Family 65, 574-583.

61. Umberson, D., Pudrovska, T., Reczek, C., 2010. Parenthood, Childlessness, and Well-Being: A Life Course Perspective. Journal of Marriage and Family 72, 612-629.

62. Umberson, D., Williams, K., Powers, D.A., Chen, M.D., Campbell, A.M., 2005. As Good as it Gets? A Life Course Perspective on Marital Quality. Social Forces 84, 493-511.

63. von Scheve, C., Esche, F., Schupp, J., 2017. The Emotional Timeline of Unemployment: Anticipation, Reaction, and Adaptation. Journal of Happiness Studies 18, 1231-1254.

64. White, L., Edwards, J.N., 1990. Emptying the Nest and Parental Well-Being: An Analysis of National Panel Data. American Sociological Review 55, 235-242.

65. Wolbring, T., 2017. Home sweet home! Does moving have (lasting) effects on housing satisfaction? Journal of Happiness Studies 18, 1359-1375.

66. Zoch, G., Hondralis, I., 2017. The expansion of low-cost, state-subsidized childcare availability and mothers' return-to-work behaviour in East and West Germany. European Sociological Review 33, 693-707. 
APPENDIX A - Supplementary Tables \& Figures

Table A 1: Sample descriptives for the dummy impact function analysis.

\begin{tabular}{lcccc}
\hline & $(1)$ & $(2)$ & $(3)$ & $(4)$ \\
\hline & \multicolumn{2}{c}{ Treated } & \multicolumn{2}{c}{ Non-treated } \\
& Mother & Father & Mother & Father \\
\hline Life satisfaction & 6.84 & 6.83 & 7.14 & 7.20 \\
Age & 48.65 & 50.41 & 42.52 & 42.37 \\
Years of schooling & 11.74 & 12.20 & 12.01 & 12.40 \\
East Germany (0/1) & 0.26 & 0.26 & 0.23 & 0.21 \\
In labor force (0/1), & 0.62 & 0.83 & 0.52 & 0.85 \\
1 year lagged & & & & \\
Working full-time & 0.33 & 0.81 & 0.27 & 0.81 \\
(0/1), 1 year lagged & & & & \\
Married (0/1) & 0.75 & 0.83 & 0.69 & 0.75 \\
Still children in the & 0.75 & 0.74 & 0.64 & 0.69 \\
house (0/1) & & & & \\
Number of children & 2.25 & 2.03 & 1.88 & 1.85 \\
\hline Observations & 59890 & 51188 & 95215 & 65498 \\
\hline
\end{tabular}


Table A 2: Dummy impact function results (corresponding to Fig. 2 to 5).

\begin{tabular}{|c|c|c|c|c|c|c|c|c|}
\hline & $(1)$ & (2) & (3) & (4) & $(5)$ & $(6)$ & (7) & $(8)$ \\
\hline & \multicolumn{3}{|c|}{$\begin{array}{l}\text { Launching phase } \\
\text { West Germany }\end{array}$} & \multicolumn{3}{|c|}{$\begin{array}{c}\text { Empty Nest } \\
\text { West Germany }\end{array}$} & \multicolumn{2}{|c|}{$\begin{array}{l}\text { Launching phase } \\
\text { East Germany }\end{array}$} \\
\hline & All & Mothers & Fathers & All & Mothers & Fathers & Mothers & Fathers \\
\hline-5 & $\begin{array}{c}0.041 \\
(0.021)\end{array}$ & $\begin{array}{c}0.062^{*} \\
(0.029)\end{array}$ & $\begin{array}{c}0.017 \\
(0.031)\end{array}$ & $\begin{array}{c}-0.017 \\
(0.029)\end{array}$ & $\begin{array}{c}0.002 \\
(0.040)\end{array}$ & $\begin{array}{l}-0.038 \\
(0.043)\end{array}$ & $\begin{array}{c}0.024 \\
(0.049)\end{array}$ & $\begin{array}{c}0.055 \\
(0.053)\end{array}$ \\
\hline-4 & $\begin{array}{l}0.064^{* *} \\
(0.020)\end{array}$ & $\begin{array}{c}0.050 \\
(0.028)\end{array}$ & $\begin{array}{l}0.079^{* *} \\
(0.029)\end{array}$ & $\begin{array}{c}0.021 \\
(0.028)\end{array}$ & $\begin{array}{c}0.006 \\
(0.040)\end{array}$ & $\begin{array}{c}0.041 \\
(0.040)\end{array}$ & $\begin{array}{c}0.030 \\
(0.047)\end{array}$ & $\begin{array}{c}0.004 \\
(0.050)\end{array}$ \\
\hline-3 & $\begin{array}{c}0.014 \\
(0.020)\end{array}$ & $\begin{array}{l}-0.019 \\
(0.027)\end{array}$ & $\begin{array}{c}0.052 \\
(0.028)\end{array}$ & $\begin{array}{l}-0.012 \\
(0.029)\end{array}$ & $\begin{array}{l}-0.034 \\
(0.040)\end{array}$ & $\begin{array}{c}0.016 \\
(0.041)\end{array}$ & $\begin{array}{l}-0.067 \\
(0.045)\end{array}$ & $\begin{array}{c}0.015 \\
(0.047)\end{array}$ \\
\hline-2 & $\begin{array}{c}0.023 \\
(0.019)\end{array}$ & $\begin{array}{c}0.014 \\
(0.026)\end{array}$ & $\begin{array}{c}0.034 \\
(0.026)\end{array}$ & $\begin{array}{c}0.005 \\
(0.027)\end{array}$ & $\begin{array}{c}0.027 \\
(0.038)\end{array}$ & $\begin{array}{l}-0.017 \\
(0.038)\end{array}$ & $\begin{array}{c}0.031 \\
(0.044)\end{array}$ & $\begin{array}{c}-0.002 \\
(0.047)\end{array}$ \\
\hline-1 & Ref. & & & & & & & \\
\hline 0 & $\begin{array}{c}-0.076^{* * *} \\
(0.020)\end{array}$ & $\begin{array}{l}-0.063^{*} \\
(0.028)\end{array}$ & $\begin{array}{c}-0.090^{* *} \\
(0.030)\end{array}$ & $\begin{array}{c}-0.033 \\
(0.027)\end{array}$ & $\begin{array}{c}0.010 \\
(0.038)\end{array}$ & $\begin{array}{l}-0.076 \\
(0.040)\end{array}$ & $\begin{array}{l}-0.063 \\
(0.047)\end{array}$ & $\begin{array}{c}-0.057 \\
(0.050)\end{array}$ \\
\hline 1 & $\begin{array}{c}-0.097^{* * *} \\
(0.021)\end{array}$ & $\begin{array}{c}-0.102^{* * *} \\
(0.029)\end{array}$ & $\begin{array}{c}-0.089^{* *} \\
(0.030)\end{array}$ & $\begin{array}{c}-0.037 \\
(0.029)\end{array}$ & $\begin{array}{l}-0.018 \\
(0.040)\end{array}$ & $\begin{array}{l}-0.052 \\
(0.043)\end{array}$ & $\begin{array}{c}0.012 \\
(0.047)\end{array}$ & $\begin{array}{c}-0.002 \\
(0.050)\end{array}$ \\
\hline 2 & $\begin{array}{c}-0.077^{* * *} \\
(0.021)\end{array}$ & $\begin{array}{l}-0.050 \\
(0.029)\end{array}$ & $\begin{array}{c}-0.107^{* * *} \\
(0.031)\end{array}$ & $\begin{array}{c}-0.008 \\
(0.031)\end{array}$ & $\begin{array}{l}-0.001 \\
(0.042)\end{array}$ & $\begin{array}{l}-0.009 \\
(0.047)\end{array}$ & $\begin{array}{l}-0.027 \\
(0.049)\end{array}$ & $\begin{array}{c}0.023 \\
(0.056)\end{array}$ \\
\hline 3 & $\begin{array}{l}-0.050^{*} \\
(0.022)\end{array}$ & $\begin{array}{l}-0.055 \\
(0.031)\end{array}$ & $\begin{array}{l}-0.044 \\
(0.032)\end{array}$ & $\begin{array}{c}-0.033 \\
(0.034)\end{array}$ & $\begin{array}{l}-0.056 \\
(0.047)\end{array}$ & $\begin{array}{c}0.003 \\
(0.050)\end{array}$ & $\begin{array}{c}-0.044 \\
(0.050)\end{array}$ & $\begin{array}{c}-0.010 \\
(0.054)\end{array}$ \\
\hline 4 & $\begin{array}{c}-0.083^{* * *} \\
(0.023)\end{array}$ & $\begin{array}{c}-0.086^{* *} \\
(0.031)\end{array}$ & $\begin{array}{l}-0.076^{*} \\
(0.034)\end{array}$ & $\begin{array}{l}-0.007 \\
(0.035)\end{array}$ & $\begin{array}{l}-0.017 \\
(0.048)\end{array}$ & $\begin{array}{c}0.016 \\
(0.052)\end{array}$ & $\begin{array}{l}-0.072 \\
(0.049)\end{array}$ & $\begin{array}{c}-0.066 \\
(0.057)\end{array}$ \\
\hline 5 & $\begin{array}{c}-0.079^{* * *} \\
(0.023)\end{array}$ & $\begin{array}{l}-0.078^{*} \\
(0.031)\end{array}$ & $\begin{array}{l}-0.075^{*} \\
(0.034)\end{array}$ & $\begin{array}{l}-0.005 \\
(0.041)\end{array}$ & $\begin{array}{l}-0.056 \\
(0.056)\end{array}$ & $\begin{array}{c}0.070 \\
(0.059)\end{array}$ & $\begin{array}{l}-0.085 \\
(0.054)\end{array}$ & $\begin{array}{c}-0.003 \\
(0.059)\end{array}$ \\
\hline 6 & $\begin{array}{l}-0.029 \\
(0.024)\end{array}$ & $\begin{array}{l}-0.013 \\
(0.032)\end{array}$ & $\begin{array}{l}-0.043 \\
(0.037)\end{array}$ & $\begin{array}{c}0.069 \\
(0.044)\end{array}$ & $\begin{array}{c}0.064 \\
(0.058)\end{array}$ & $\begin{array}{c}0.087 \\
(0.067)\end{array}$ & $\begin{array}{l}-0.021 \\
(0.056)\end{array}$ & $\begin{array}{c}-0.052 \\
(0.059)\end{array}$ \\
\hline 7 & $\begin{array}{c}-0.067^{* *} \\
(0.025)\end{array}$ & $\begin{array}{l}-0.065 \\
(0.034)\end{array}$ & $\begin{array}{l}-0.065 \\
(0.037)\end{array}$ & $\begin{array}{c}0.025 \\
(0.046)\end{array}$ & $\begin{array}{l}-0.001 \\
(0.062)\end{array}$ & $\begin{array}{c}0.070 \\
(0.070)\end{array}$ & $\begin{array}{l}-0.082 \\
(0.057)\end{array}$ & $\begin{array}{c}-0.080 \\
(0.064)\end{array}$ \\
\hline 8 & $\begin{array}{l}-0.027 \\
(0.026)\end{array}$ & $\begin{array}{l}-0.026 \\
(0.035)\end{array}$ & $\begin{array}{l}-0.021 \\
(0.039)\end{array}$ & $\begin{array}{c}0.091 \\
(0.050)\end{array}$ & $\begin{array}{c}0.068 \\
(0.068)\end{array}$ & $\begin{array}{c}0.135 \\
(0.076)\end{array}$ & $\begin{array}{c}-0.043 \\
(0.056)\end{array}$ & $\begin{array}{c}-0.040 \\
(0.067)\end{array}$ \\
\hline 9 & $\begin{array}{l}-0.064^{*} \\
(0.027)\end{array}$ & $\begin{array}{l}-0.088^{*} \\
(0.036)\end{array}$ & $\begin{array}{l}-0.028 \\
(0.040)\end{array}$ & $\begin{array}{c}0.118^{*} \\
(0.054)\end{array}$ & $\begin{array}{c}0.074 \\
(0.072)\end{array}$ & $\begin{array}{c}0.191^{*} \\
(0.082)\end{array}$ & $\begin{array}{l}-0.052 \\
(0.061)\end{array}$ & $\begin{array}{c}0.030 \\
(0.069)\end{array}$ \\
\hline 10 & $\begin{array}{l}-0.044 \\
(0.028) \\
\end{array}$ & $\begin{array}{c}-0.066 \\
(0.038) \\
\end{array}$ & $\begin{array}{l}-0.008 \\
(0.043) \\
\end{array}$ & $\begin{array}{c}0.034 \\
(0.059) \\
\end{array}$ & $\begin{array}{l}-0.043 \\
(0.076) \\
\end{array}$ & $\begin{array}{c}0.155 \\
(0.093) \\
\end{array}$ & $\begin{array}{l}-0.121^{*} \\
(0.059) \\
\end{array}$ & $\begin{array}{c}0.024 \\
(0.071) \\
\end{array}$ \\
\hline$N$ & 207045 & 117328 & 89717 & 203101 & 116976 & 86125 & 37777 & 26969 \\
\hline
\end{tabular}

Standard errors in parentheses. Significance levels: ${ }^{*} p<0.05,{ }^{* *} p<0.01,{ }^{* * *} p<0.001$ 
Table A 3: Channels by gender - fixed effects.

\begin{tabular}{lcccc}
\hline & $\begin{array}{c}(1) \\
\text { Housework (hours } \\
\text { per day) }\end{array}$ & $\begin{array}{c}(2) \\
\text { Satisfaction } \\
\text { leisure }\end{array}$ & $\begin{array}{c}\text { Satisfaction household } \\
\text { income }\end{array}$ & $\begin{array}{c}\text { Satisfaction } \\
\text { family life }\end{array}$ \\
\hline $\begin{array}{l}\text { First child moved out } \\
\text { X Father }\end{array}$ & $0.249^{* * *}$ & -0.027 & $-0.139^{* * *}$ & $-0.167^{* * *}$ \\
& $(0.017)$ & $(0.032)$ & $(0.029)$ & $(0.045)$ \\
First child moved out & $-0.270^{* * *}$ & 0.042 & $-0.107^{* * *}$ & -0.068 \\
X Mother & $(0.021)$ & $(0.033)$ & $(0.030)$ & $(0.044)$ \\
\hline$N$ & 79087 & 78483 & 81537 & 35069 \\
\hline
\end{tabular}

Standard errors in parentheses. Controls as in Table 2.

Significance levels: ${ }^{*} p<0.05,{ }^{* *} p<0.01,{ }^{* * *} p<0.001$ 


\section{APPENDIX B - Identification of Moves}

Moves of children are mainly identified through the SOEP question on whether a child moved out during the last year. This question is in the survey from 1999 on. Furthermore, to use the full potential of the data, we also identify children moving out with the following criteria. We identify a child moving out if the number of children in the household above the age of 16 is lower compared to the previous panel wave (which gives us 10,010 moves) or if the householdID of a child above the age of 16 changed, but the parental household-ID remains the same (which further identifies 2,090 previously not identified moves).

Furthermore, we classify a move as an empty nest move, if there the household-ID of the parental household remains constant, but the number of children above the age of 16 changes to zero and we also have previously identified a move.

Additionally, we delete implausible moves from our data. Implausible moves are moves, in which no child was in the household in the previous wave and there is no child in the household now, but the respondent still said that a child moved out ( 872 cases). This could also be children that e.g. went to college, came back for some month when looking for a job and moved out again, but even in this case, we consider this as a child that has moved out previously. Furthermore, we delete all moves in which the respective parent is younger than 35 at the time the move occurs (271 cases) Overall, we observe between 419 (1994) and 1039 (2016) moves, averaging 696 moves per survey year. 